\title{
Aqueous Extract of Saraca indica Leaves in the Synthesis of Copper Oxide Nanoparticles: Finding a Way towards Going Green
}

\author{
Kollur Shiva Prasad, ${ }^{1}$ Alakananda Patra, ${ }^{1}$ Govindaraju Shruthi, ${ }^{2}$ and Shivamallu Chandan ${ }^{2}$ \\ ${ }^{1}$ Laboratory of Synthetic and Materials Chemistry, Manipal Centre for Natural Sciences, Manipal University, Udupi, \\ Karnataka 576 104, India \\ ${ }^{2}$ Division of Biotechnology and Bioinformatics, Faculty of Life Sciences, Jagadguru Sri Shivarathreeshwara University, \\ Mysuru, Karnataka 570 015, India \\ Correspondence should be addressed to Kollur Shiva Prasad; shivaprasad.k@manipal.edu
}

Received 3 November 2016; Revised 5 January 2017; Accepted 5 February 2017; Published 22 February 2017

Academic Editor: Marco Rossi

Copyright (C) 2017 Kollur Shiva Prasad et al. This is an open access article distributed under the Creative Commons Attribution License, which permits unrestricted use, distribution, and reproduction in any medium, provided the original work is properly cited.

\begin{abstract}
The present study is mainly aimed at the synthesis of copper oxide nanoparticles of varied size by green synthetic approach. The structural and morphological behavior of as-synthesized $\mathrm{CuO}$ nanoparticles were investigated using ultraviolet-visible spectral studies (UV-Vis), Fourier transform-Infrared spectroscopy (FT-IR), X-ray diffraction (XRD), energy dispersive X-ray spectroscopy (EDX), X-ray photoelectron spectroscopy (XPS), scanning electron microscopy (SEM), transmission electron microscopy (TEM), and high-resolution transmission electron microscopy (HRTEM). The reduction of copper ions using aqueous extract of $S$. indica leaves produces nanoparticles of varied size and morphology. The images from SEM investigation revealed that the particles are spherical in shape with average diameter of 40-70 $\mathrm{nm}$. TEM and HRTEM images clearly indicate the crystallinity and spherical nature of as-synthesized $\mathrm{CuO}$ nanoparticles with interplanar distance between two neighboring lattice fringes of $0.315 \mathrm{~nm}$.
\end{abstract}

\section{Introduction}

Cupric oxide $(\mathrm{CuO})$ nanoarchitectures are of special interest because of their interesting properties and promising applications in batteries, solar cells, gas-sensors, biosensors, catalysis, photodetectors, and removal of toxic pollutants from waste water [1]. Due to some toxic chemicals absorbed on the surface of nanoparticles when they are prepared by conventional chemical methods and that may cause adverse effects in medical applications, researchers are constantly making enormous findings in synthesizing nanoparticles by green approach. Very recently, eco-friendly synthesis of various nanoparticles by plants such as neem [2], alfalfa [3,4], Cinnamomum camphora [5], Emblica officinalis [6], lemon grass [7], and tamarind [8] have been reported. Saraca indica, commonly known as Ashoka tree, is generally found in the Western Ghats of Indian subcontinent. Till date, the use of extract from this plant is limited and thus we approached synthesizing $\mathrm{CuO}$ NPs using aqueous extract of leaves of Ashoka tree.

Herein, we describe the synthesis of $\mathrm{CuO}$ nanoparticles by reducing copper ions using natural reducing agent, Saraca indica leaf extract. In addition, the used plant extract also served as capping agent in stabilizing the as-synthesized $\mathrm{CuO}$ NPs. The varied size and morphology of the obtained nanostructures were characterized using FT-IR, UV-Vis, XRD, EDX, XPS, SEM, TEM, HRTEM, and SAED techniques. In addition, the photoluminescence behavior of $\mathrm{CuO}$ NPs under study was described.

\section{Experimental}

2.1. Materials and Methods. Starting material, hydrated copper chloride $\left[\mathrm{CuCl}_{2} \cdot \mathrm{H}_{2} \mathrm{O}\right]$ procured from Sigma (USA), and acetone were obtained from Merck chemical suppliers, India. Deionized water collected from ELGA purifier was used 
throughout the experimentation. The electronic absorption spectra were obtained using Perkin Elmer Lambda 750 UVVisible spectrometer. The fluorescence studies were performed on Horiba JOBIN YVON Fluoromax-4 spectrometer. FT-IR spectra were obtained on IR spectrometer (Shimadzu). Powder XRD was recorded on Bruker X-ray diffractometer using a $\mathrm{Cu} \mathrm{K} \alpha(1.5406 \AA)$ radiation. X-ray photoelectron spectroscopy (XPS) was recorded using a MULTILAB 2000, Thermo Scientific, UK. Energy dispersive spectra (EDS) was recorded using HITACH S-2400 energy dispersive X-ray spectrometer. Scanning electron microscopy (SEM) images and X-ray mapping were recorded on Zeiss microscope. Transmission electron microscopy (TEM) images and SAED pattern were recorded on JEOL 2100F FEG operating at $200 \mathrm{kV}$ after casting a drop of CuO NPs dispersion in ethanol over $\mathrm{Cu}$ grid.

2.2. Plant Material Collection and Extraction. S. indica was collected from Udupi, Karnataka, India, during July to August 2016. The plant identification was explicitly performed by Dr. K. Shiva Prasad. The leaves were thoroughly washed and dried at room temperature for about 10 days and ground into a fine powder. The dried leaves $(23.5 \mathrm{~g})$ were extracted with water as a solvent by a soxhlet apparatus at $60^{\circ} \mathrm{C}(1: 4 \mathrm{w} / \mathrm{v})$. The obtained filtrate was reduced under rotary vacuum evaporator (Buchi) resulting in $7.8 \%$ of aqueous extract of $S$. indica leaves.

2.3. Synthesis of $\mathrm{CuO}$ Nanoparticles. To an aqueous solution of $\mathrm{CuCl}_{2} \cdot \mathrm{H}_{2} \mathrm{O}(1.34 \mathrm{~g}$ in $25 \mathrm{~mL})$, S. indica leaf extract was added $(0.29 \mathrm{~g}$ dissolved in $20 \mathrm{~mL}$ deionized water $)$ and stirred for $1 \mathrm{~h}$. The formation of ruby red colored solution from the above reaction mixture implies the formation of $\mathrm{CuO}$ NPs. The stirring was continued for another $2 \mathrm{~h}$ to obtain dark brown colored solution suggesting the formation of stabilized copper oxide nanoparticles. It was then filtered and washed with water followed by acetone and dried at $100^{\circ} \mathrm{C}$ for $6 \mathrm{~h}$.

\section{Result and Discussions}

3.1. UV-Visible Absorption Spectra. Light absorption by a material leads to transmission of an electron into the conduction band and formation of a positive hole in the valence band. The UV-Visible absorption spectral studies of assynthesized copper oxide nanoparticles were performed in a homogeneously suspended ethanol solution and are depicted in Figure 1. A strong absorption peak observed at around $213 \mathrm{~nm}$ was because of direct transition of electrons [9] and another absorption peak observed at $339 \mathrm{~nm}$ indicates the presence of optical band gap in $\mathrm{CuO}$ NPs (concentration is $0.1341 \mathrm{mg} / \mathrm{mL}$ ). This kind of optical absorption permits us to determine the crystallinity of material upon comparison of their band gaps. These observations are consistent with the previously reported studies $[10,11]$.

3.2. FT-IR Spectroscopy. Figure 2 shows infrared spectra of obtained CuO NPs. A broadband at $3422 \mathrm{~cm}^{-1}$ is attributed to intermolecular hydrogen bonding between hydroxyl groups

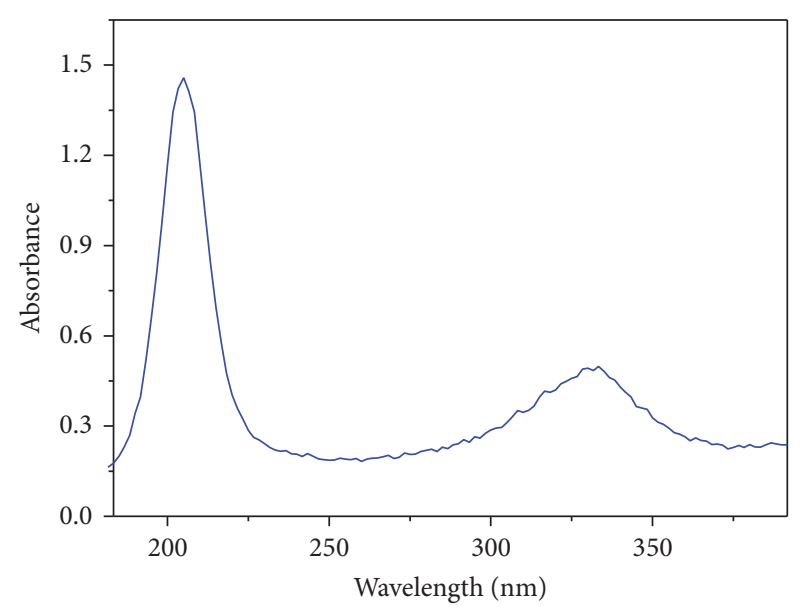

FIGURE 1: UV-visible spectra of CuO NPs synthesized using aqueous extract of $S$. indica leaves.

of benzene ring containing acids and/or alcohol compounds [12]. The band observed at $1635 \mathrm{~cm}^{-1}$ is due to $\mathrm{C}=\mathrm{O}$ stretching of ketones and/or acids [13] present in the residual plant material. A narrow band was noticed at $575 \mathrm{~cm}^{-1}$ confirming the formation of pure $\mathrm{CuO}$ NPs.

3.3. XRD Measurements. As depicted in Figure 3, XRD patterns of as-synthesized $\mathrm{CuO}$ NPs are typical and are similar to the single phase monoclinic structure with a lattice constant $a=4.6961 \AA$ and $b=3.4320 \AA$ and $c=5.1330 \AA$ and $\beta$ $=99.5284^{\circ}$. The distinctive peaks located at $2 \theta=32.94^{\circ}, 35.83^{\circ}$, $39.62^{\circ}, 59.02^{\circ}, 60.71^{\circ}$, and $64.89^{\circ}$ are assigned to (110), (002), (200), (202), and (202) plane orientation of CuO (JCPDS 801268). It clearly revealed that nanosized $\mathrm{CuO}$ was successfully synthesized under current mild experimental conditions.

3.4. XPS Studies. Figure 4 shows XPS spectra of assynthesized $\mathrm{CuO}$ NPs. The peaks centred at $939.87 \mathrm{eV}$ and $954.57 \mathrm{eV}$ corresponded to the $\mathrm{Cu} 2 \mathrm{p}_{3 / 2}$ and $\mathrm{Cu} 2 \mathrm{p}_{1 / 2}$, respectively. The higher binding energy of $\mathrm{Cu} 2 \mathrm{p}_{3 / 2}$ at $939.87 \mathrm{eV}$ and the presence of shake-up peak at about $945-950 \mathrm{eV}$ were two major XPS characteristics of $\mathrm{CuO}$, indicating the existence of $\mathrm{Cu}^{2+}[14,15]$.

3.5. EDX Investigations. The purity of the as-synthesized $\mathrm{CuO}$ NPs was investigated by EDX spectral measurements. The EDX spectra shown in Figure 5 reveals that the sample contains $\mathrm{Cu}, \mathrm{O}$, and $\mathrm{Si}$. The presence of $\mathrm{Si}$ was due to the sample holder which might have appeared during sample preparation. This clearly indicates that the sample under investigation is free from impurity. Thus, the aqueous extract of leaves of $S$. indica is found to be a powerful eco-friendly reductant for reducing metal salts into their nanostructures.

3.6. SEM Analysis. The morphologies of as-synthesized $\mathrm{CuO}$ NPs are analyzed by SEM measurements, illustrated in 


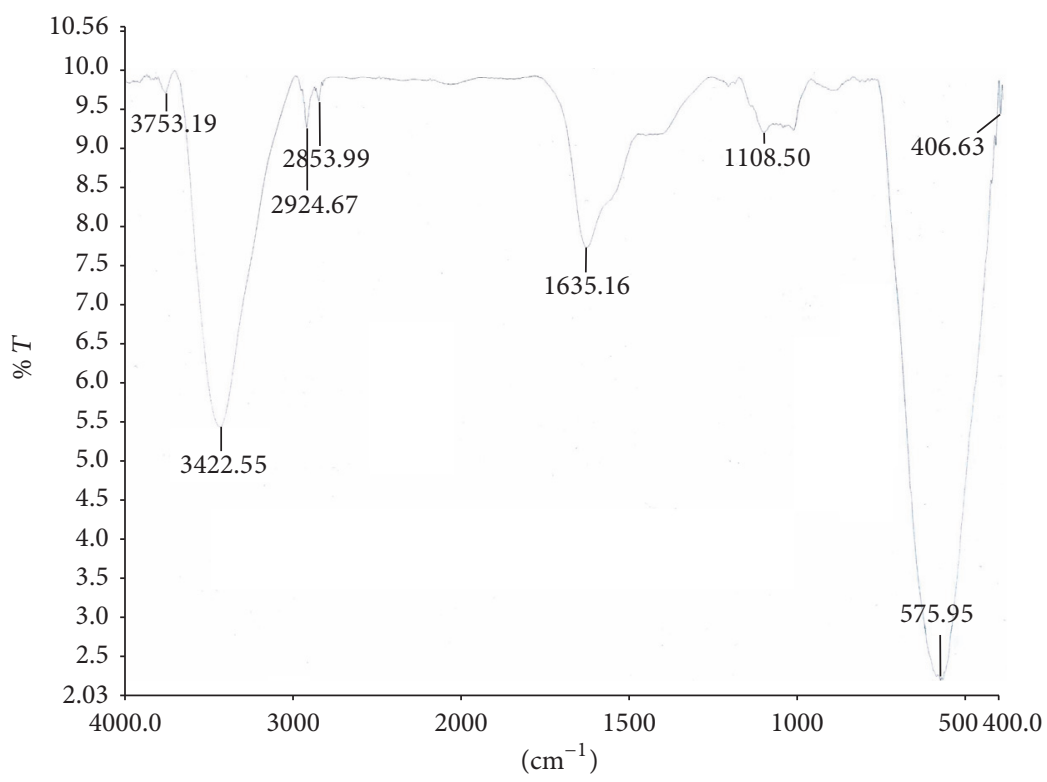

FIGURE 2: Infrared spectrum of prepared CuO NPs.

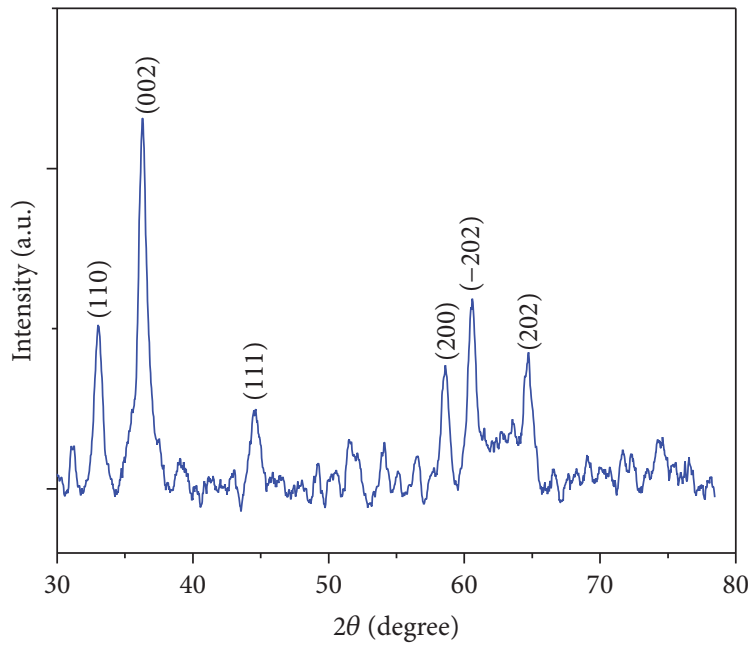

Figure 3: X-ray diffraction pattern of CuO NPs synthesized using aqueous extract of Saraca indica leaves.

Figure 6. From the SEM images, it can be clearly seen that assynthesized $\mathrm{CuO}$ NPs mainly comprised of spherical agglomerates. The diameter of well-defined and fully developed agglomerate of as-synthesized $\mathrm{CuO}$ NPs varies between 40 and $70 \mathrm{~nm}$.

3.7. TEM Investigations. Figure 7 depicts typical TEM images of as-synthesized $\mathrm{CuO}$ nanoparticles. The TEM image (Figure $7(a)$ ) reveals that the product comprises spherical particles with a uniform morphology and size distribution with particle size in the range of $13-15 \mathrm{~nm}$. High-resolution TEM (HRTEM) image of as-synthesized $\mathrm{CuO}$ nanoparticles is shown in Figure 7(b). The crystalline nature of the nanoparticles is clearly seen from the images shown in lattice fringes

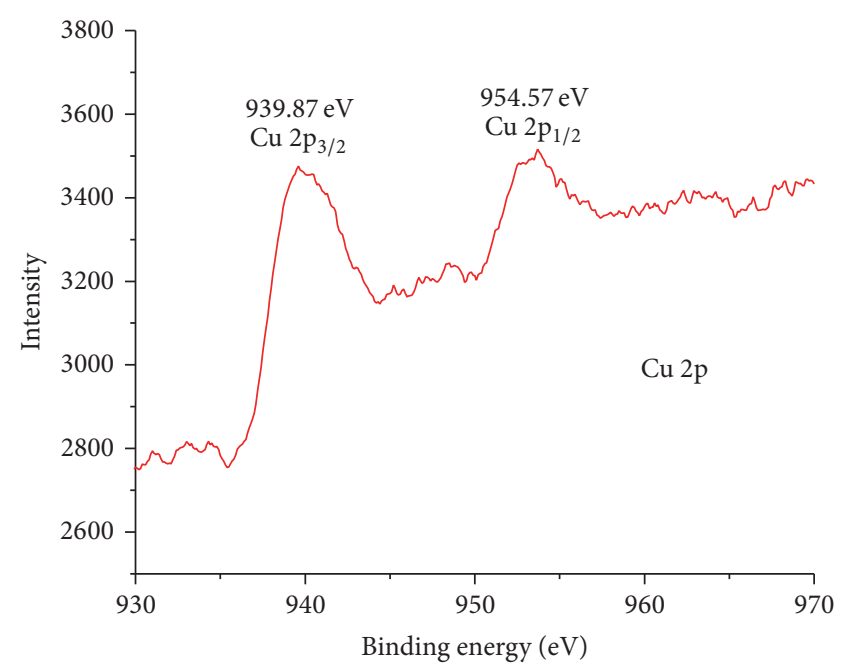

FIGURE 4: XPS spectra of as-synthesized $\mathrm{CuO}$ nanoparticles.

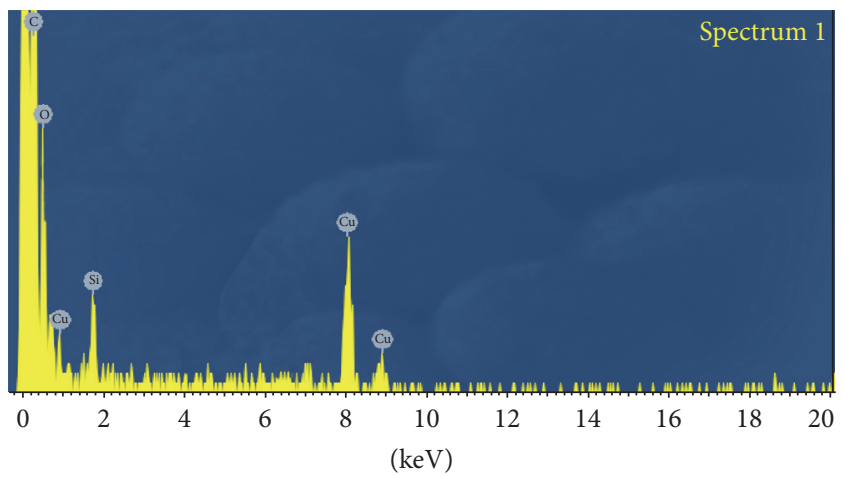

Full scale 39 cts cursor: 20.039 ( 1 cts)

FIGURE 5: EDX results obtained for CuO NPs under study. 


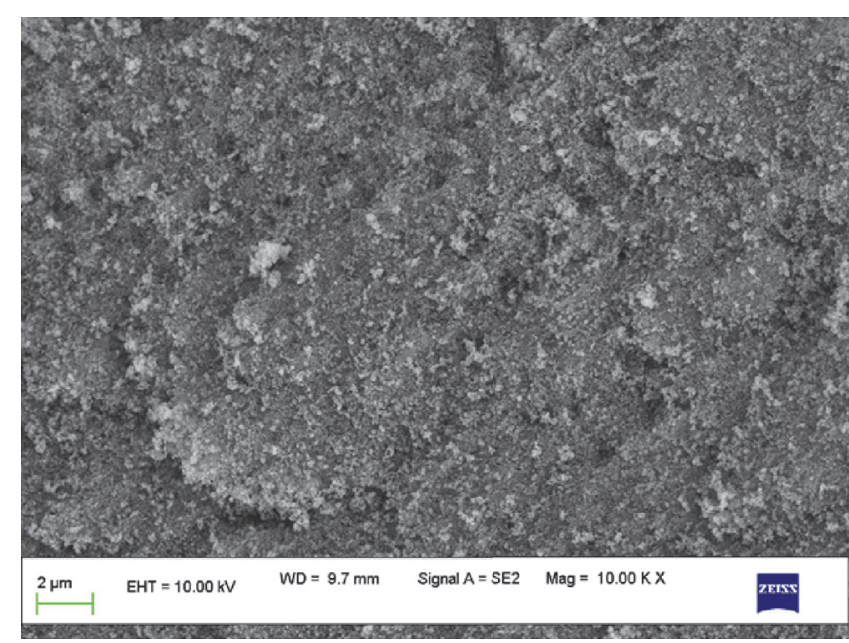

(a)

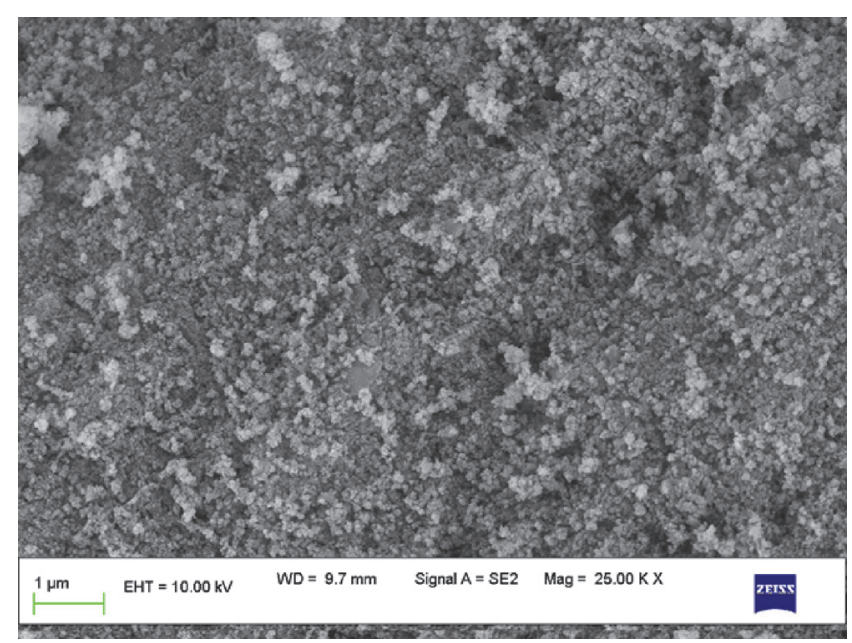

(b)

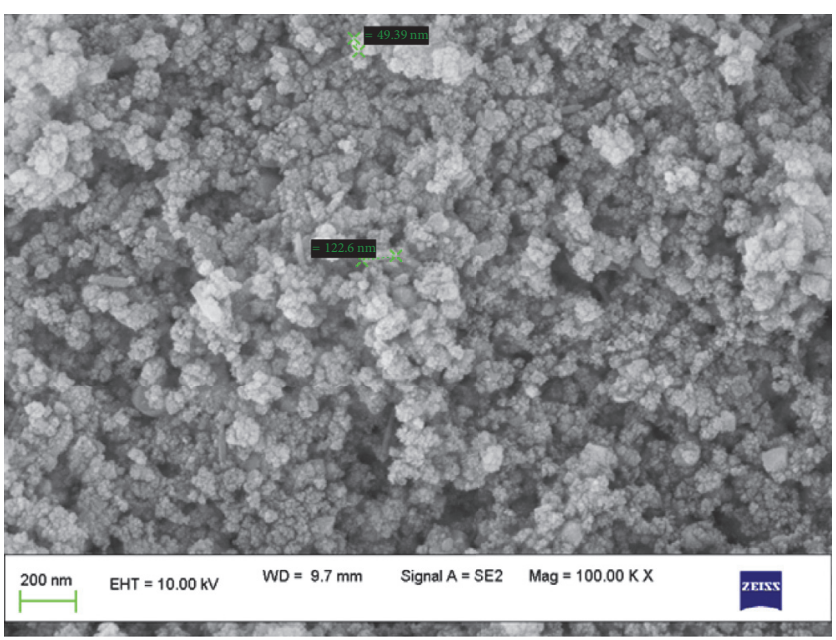

(c)

FIGURE 6: SEM images of as-prepared copper oxide nanoparticles.

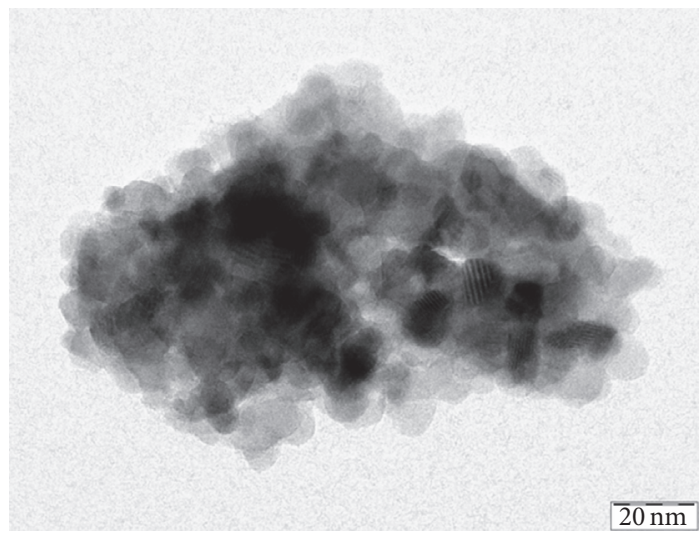

(a)

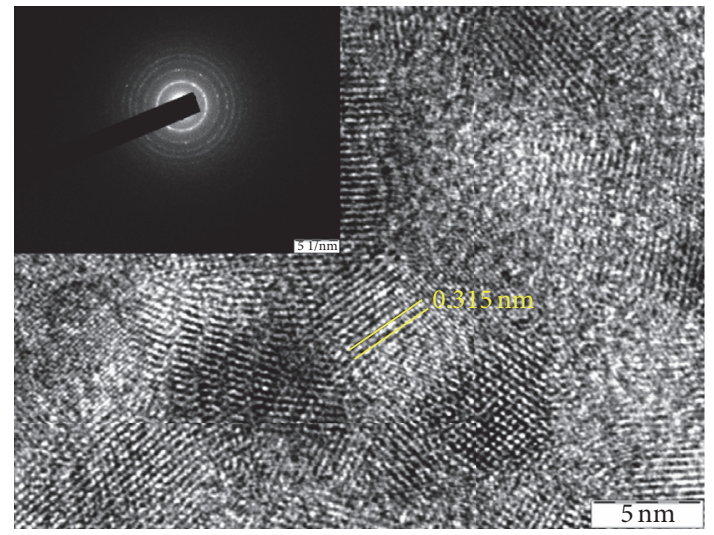

(b)

FIGURE 7: TEM images showing (a) spherical nature of as-synthesized $\mathrm{CuO}$ nanoparticles and (b) HRTEM image of CuO NPs and SAED pattern (inset image). 


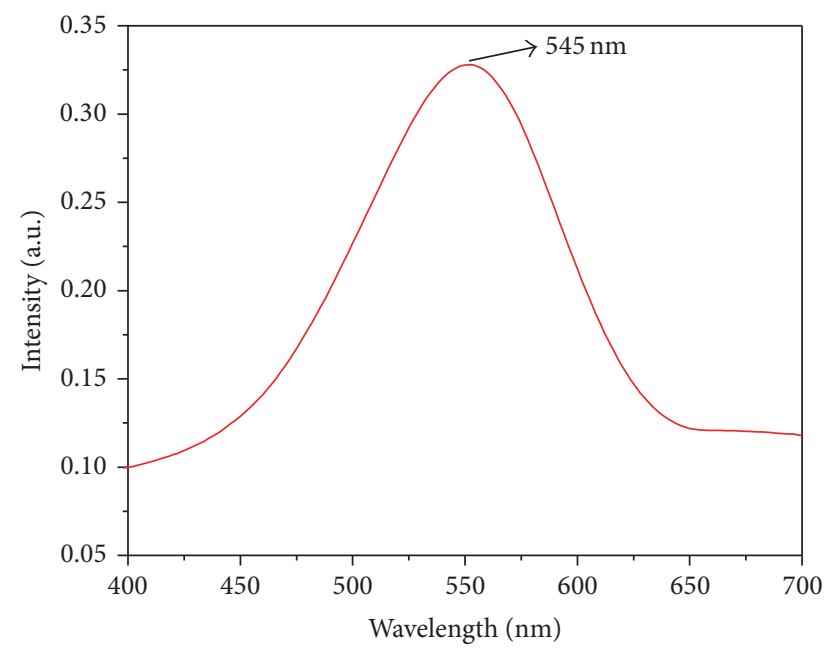

Figure 8: Fluorescence emission spectra of as-synthesized $\mathrm{CuO}$ nanoparticles in ethanol medium.

and the interplanar distance between two neighboring fringes is about $0.315 \mathrm{~nm}$. The SAED pattern (inset in Figure 7(b)) reveals the single-crystalline nature of the $\mathrm{CuO}$ nanospheres. The size of the particles observed from TEM and HRTEM investigations is in good agreement with XRD diffraction pattern, confirming good crystallinity of the $\mathrm{CuO}$ nanospheres.

3.8. Photoluminescence Studies. The dispersed ethanolic solution of as-synthesized $\mathrm{CuO}$ NPs was used for photoluminescence measurements at room temperature. The broad emission maximum observed at $545 \mathrm{~nm}\left(\lambda_{\mathrm{ex}}=350 \mathrm{~nm}\right)$ in Figure 8 corresponds to band edge emission in $\mathrm{CuO}$ NPs which coincides well with the previous reports $[16,17]$. The relatively low fluorescence emission maxima observed may be due to the luminescence arising from the recombination of excitons and/or shallowly trapped electron-hole pairs [18]. Thus, it clearly indicates that particles are fluorescent but not intensely fluorescent.

\section{Conclusions}

Facile synthesis of $\mathrm{CuO}$ NPs using $S$. indica leaf extract has been demonstrated. The self-accumulated nanospheres of copper oxide nanoparticles were prepared by using naturally occurring plant, Saraca indica (aqueous extract) as reducing and stabilizing agent. The 3D nanospheres have an average diameter of about $13-15 \mathrm{~nm}$. The formation of $\mathrm{CuO}$ NPs was primarily noticed by observing color change during their synthesis and also by encountering a characteristic IR band at $575 \mathrm{~cm}^{-1}$, attributed for $\mathrm{Cu}-\mathrm{O}$ stretching vibrations. The morphology and crystal structure investigations by SEM, TEM, and HRTEM revealed the spherical nature of as-prepared $\mathrm{CuO}$ NPs with interplanar spacing $0.315 \mathrm{~nm}$ in the single crystal of $\mathrm{CuO}$. The fluorescence emission intensity observed at $518 \mathrm{~nm}$ in the reported $\mathrm{CuO}$ NPs was due to recombination of excitons and/or shallowly trapped electron-hole pairs. Thus, these could find interesting applications in fluorescenceemitting materials.

\section{Competing Interests}

The authors declare that they have no conflict of interests in the publishing of this research work.

\section{Acknowledgments}

The authors gratefully thank the Director at Indian Institute of Science, Bengaluru, for providing instrumentation facilities. Special thanks are due to Dr. Mohini Gupta, Director, Manipal Centre for Natural Sciences, Manipal University, for initiating this research program and funding for current research work (start-up grant). They also extend their gratitude to the Head and Chairman, Faculty of Life Sciences, Jagadguru Sri Shivarathreeshwara University, for allowing them to perform UV-Visible spectral studies.

\section{References}

[1] Q. Zhang, K. Zhang, D. Xu et al., "CuO nanostructures: synthesis, characterization, growth mechanisms, fundamental properties, and applications," Progress in Materials Science, vol. 60, no. 1, pp. 208-237, 2014.

[2] S. S. Shankar, A. Rai, A. Ahmad, and M. Sastry, "Rapid synthesis of $\mathrm{Au}, \mathrm{Ag}$, and bimetallic Au core-Ag shell nanoparticles using Neem (Azadirachta indica) leaf broth," Journal of Colloid and Interface Science, vol. 275, no. 2, pp. 496-502, 2004.

[3] J. L. Gardea-Torresdey, J. G. Parsons, E. Gomez et al., "Formation and Growth of Au Nanoparticles inside Live Alfalfa Plants," Nano Letters, vol. 2, no. 4, pp. 397-401, 2002.

[4] J. L. Gardea-Torresdey, E. Gomez, J. R. Peralta-Videa, J. G. Parsons, H. Troiani, and M. Jose-Yacaman, "Alfalfa sprouts: a natural source for the synthesis of silver nanoparticles," Langmuir, vol. 19, no. 4, pp. 1357-1361, 2003.

[5] J. Huang, Q. Li, D. Sun et al., "Biosynthesis of silver and gold nanoparticles by novel sundried Cinnamomum camphora leaf," Nanotechnology, vol. 18, no. 10, pp. 105104-105115, 2007.

[6] B. Ankamwar, C. Damle, A. Ahmad, and M. Sastry, "Biosynthesis of gold and silver nanoparticles using Emblica Officinalis fruit extract, their phase transfer and transmetallation in an organic solution," Journal of Nanoscience and Nanotechnology, vol. 5, no. 10, pp. 1665-1671, 2005.

[7] S. S. Shankar, A. Rai, B. Ankamwar, A. Singh, A. Ahmad, and M. Sastry, "Biological synthesis of triangular gold nanoprisms," Nature Materials, vol. 3, no. 7, pp. 482-488, 2004.

[8] B. Ankamwar, M. Chaudhary, and M. Sastry, "Gold nanotriangles biologically synthesized using tamarind leaf extract and potential application in vapor sensing," Synthesis and Reactivity in Inorganic, Metal-Organic and Nano-Metal Chemistry, vol. 35, no. 1, pp. 19-26, 2005.

[9] N. R. Dhineshbabu, V. Rajendran, N. Nithyavathy, and R. Vetumperumal, "Study of structural and optical properties of cupric oxide nanoparticles," Applied Nanoscience, vol. 6, no. 6, pp. 933-939, 2016.

[10] H. Wang, J.-Z. Xu, J.-J. Zhu, and H.-Y. Chen, "Preparation of $\mathrm{CuO}$ nanoparticles by microwave irradiation," Journal of Crystal Growth, vol. 244, no. 1, pp. 88-94, 2002. 
[11] S. Tsunekawa, T. Fukuda, and A. Kasuya, "Blue shift in ultraviolet absorption spectra of monodisperse $\mathrm{CeO}_{2-x}$ nanoparticles," Journal of Applied Physics, vol. 87, no. 3, pp. 1318-1321, 2000.

[12] S. Shankar Dash, R. Majumdar, A. K. Sikder, B. Gopal Bag, and B. Kumar Patra, "Saraca indica bark extract mediated green synthesis of polyshaped gold nanoparticles and its application in catalytic reduction," Applied Nanoscience, vol. 4, no. 4, pp. 485490, 2014.

[13] P. R. Reddy, S. D. Ganesh, N. Saha, O. Zandraa, and P. Sáha, "Ecofriendly synthesis of silver nanoparticles from garden rhubarb (Rheum rhabarbarum)," Journal of Nanotechnology, vol. 2016, Article ID 4964752, 9 pages, 2016.

[14] M. S. P. Francisco, V. R. Mastelaro, P. A. P. Nascente, and A. O. Florentino, "Activity and characterization by XPS, HR-TEM, Raman spectroscopy, and bet surface area of $\mathrm{CuO} / \mathrm{CeO}_{2}-\mathrm{TiO}_{2}$ catalysts," Journal of Physical Chemistry B, vol. 105, no. 43, pp. 10515-10522, 2001.

[15] B. Wang, X.-L. Wu, C.-Y. Shu, Y.-G. Guo, and C.-R. Wang, "Synthesis of $\mathrm{CuO} / g r a p h e n e$ nanocomposite as a high-performance anode material for lithium-ion batteries," Journal of Materials Chemistry, vol. 20, no. 47, pp. 10661-10664, 2010.

[16] J. Koshy, M. Soosen Samuel, A. Chandran, and K. C. George, "Optical properties of $\mathrm{CuO}$ nanoparticles," AIP Conference Proceedings, vol. 1391, no. 1, pp. 576-578, 2011.

[17] V. Ponnarasan and A. Krishnan, "Studies on pure and divalent metal doped copper oxide nanoparticles," Advanced Studies in Theoretical Physics, vol. 8, no. 6, pp. 251-258, 2014.

[18] G. Nabiyouni and D. Ghanbari, "Thermal, magnetic, and optical characteristics of ABS- $\mathrm{Fe}_{2} \mathrm{O}_{3}$ nanocomposites," Journal of Applied Polymer Science, vol. 125, no. 4, pp. 3268-3274, 2012. 

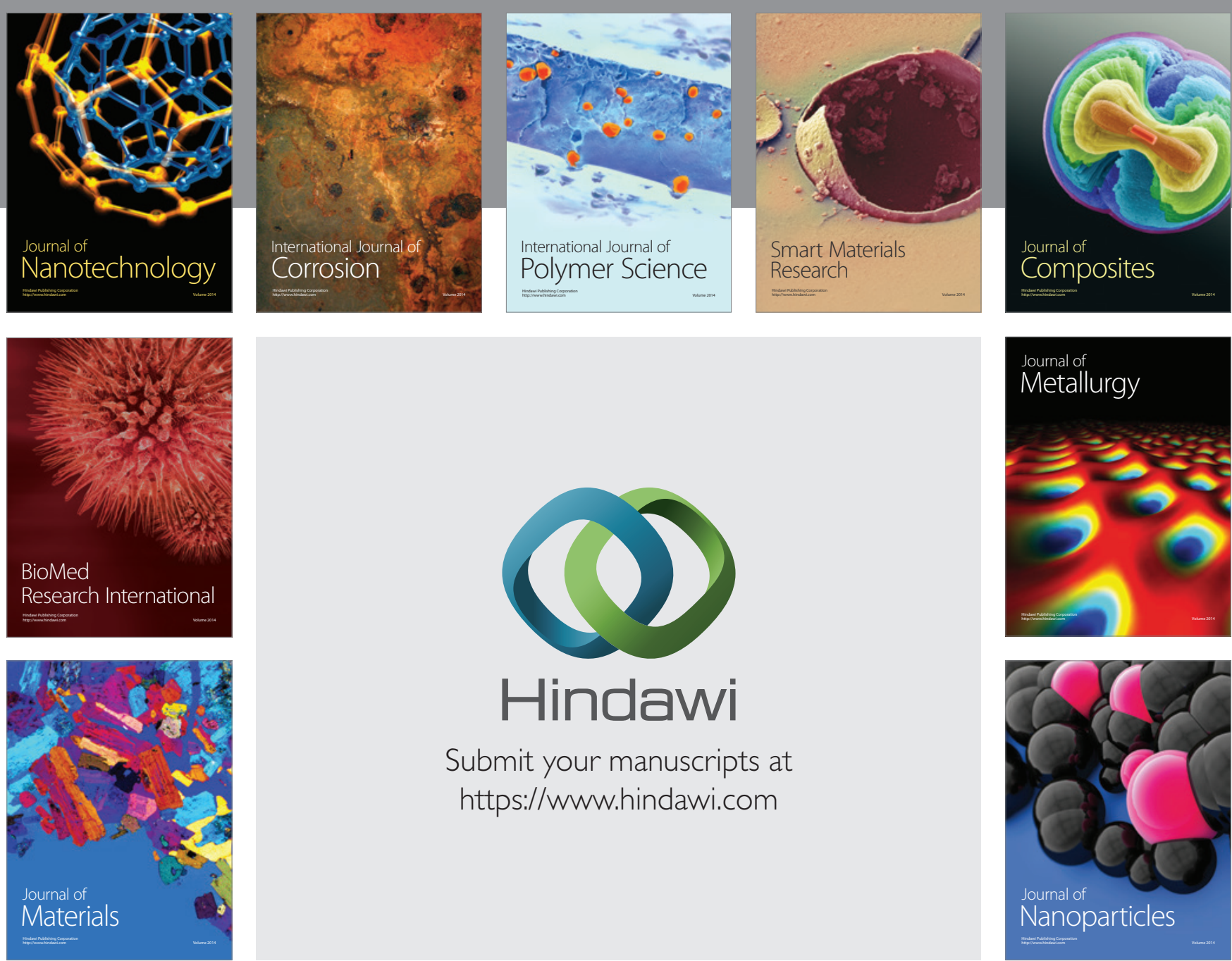

\section{Hindawi}

Submit your manuscripts at

https://www.hindawi.com

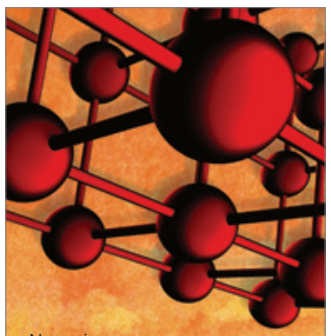

Materials Science and Engineering
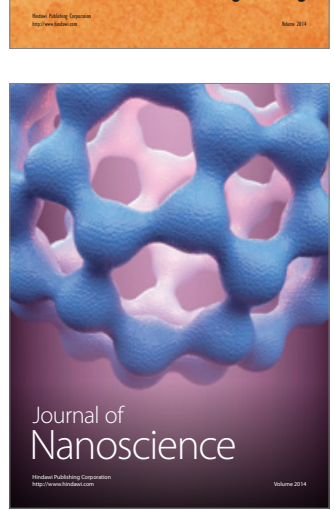
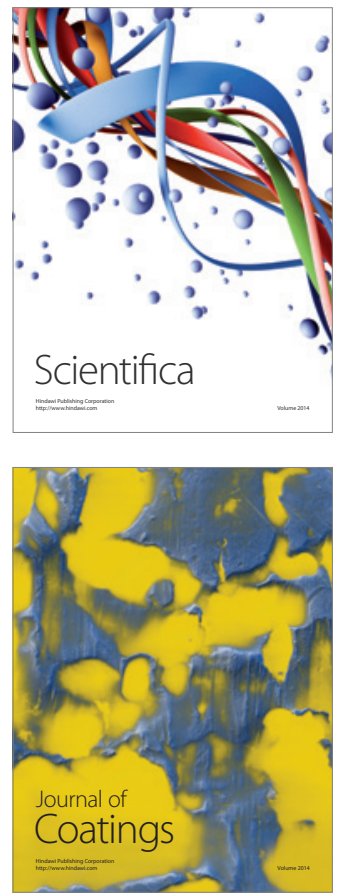
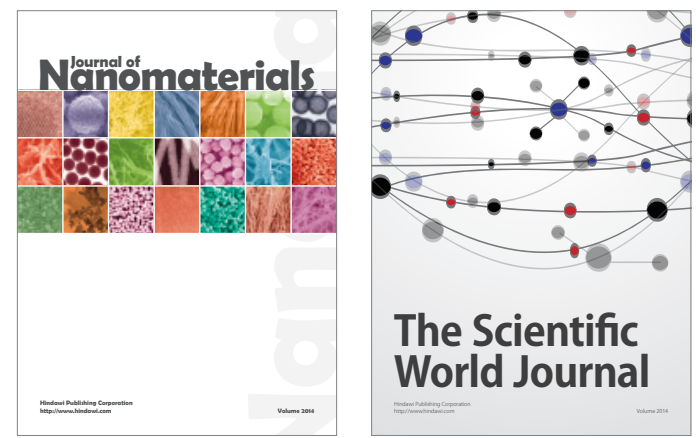

The Scientific World Journal
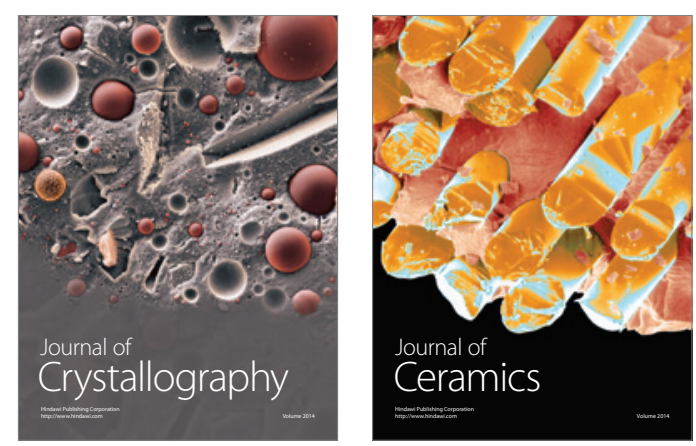
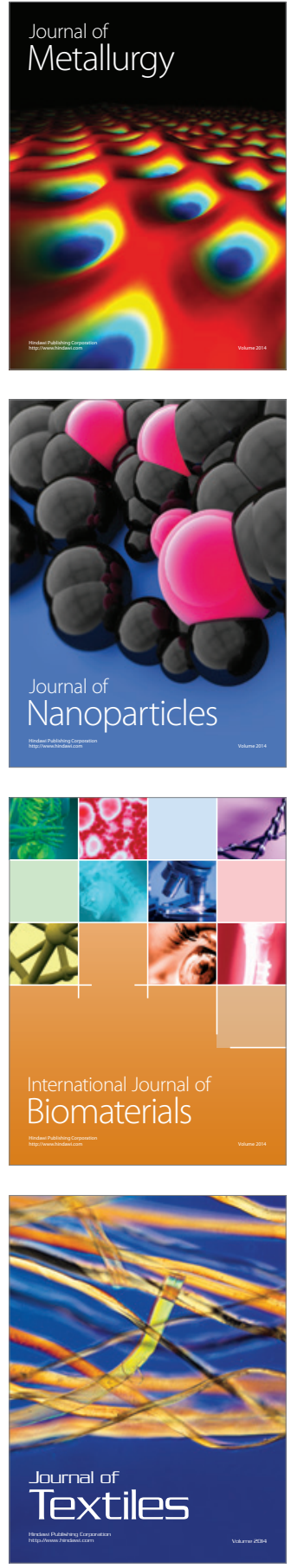